\title{
KONSEP WAKAF YANG EFEKTIF DALAM MEMBANGUN BANGSA
}

\author{
Roni Hidayat ${ }^{1}$
}

${ }^{1}$ Prodi Akuntansi Syariah, Sekolah Tinggi Ekonomi Islam SEBI, Depok, Jawa Barat. Email: ronihidayat.ma@gmail.com

\begin{abstract}
Islam has comprehensive concepts and solutions, one of them is for human socio-economic problems, therefore in Islam there are social services such as waqf. Even though Muslims realize that waqf is one of the economic sources, so far only a few have been utilized maximally and productively. There are so many waqf wealth in Indonesia. However, in general its utilization is still traditional consumptive and has not been managed productively, so it has not been right on target in solving people's socio-economic problems. The causes are: 1) Understanding of waqf that is still lacking, 2) Management of waqf that is not optimal, 3) Limited objects that are represented and the end of waqf. For this reason, it is necessary to reformulate how the concept of waqf is effective or the right target according to its function to realize social welfare in developing the nation. Namely by 1) Improving people's understanding of waqf. Endowments according to the Act. no. 41 of 2004 concerning endowments, namely: immovable property (land, buildings / parts, plants and other objects relating to land, ownership rights to units of flats, wells, other immovable property.) And movable assets (money, precious metals, letters valuable, vehicles, intellectual property rights (IPR), rental rights and other movable objects). 2) Empowerment of waqf, waqf assets mentioned above can be empowered to become productive property, profits from productive waqf can be utilized for the benefit of the ummah. 3) Management of waqf based on organizations and legal entities, this can produce professional nazhir, uniform and targeted distribution, innovative and actual fundraising. If this concept is implemented as well as possible, the primary needs of the community will be fulfilled, even social funds will also be available from the management of productive waqf.
\end{abstract}

Keywords: endowments, productive endowments, assets, effective concept.

\section{A. PENDAHULUAN}

Islam sebagai agama rahmatan lil alamin memiliki ajaran yang lengkap dan menyeluruh. Islam telah mengatur agar peradaban manusia dapat berkembang dengan baik. Agama Islam yang komprehensif telah memiliki konsep dan solusi salah satunya masalah sosial ekonomi yang akan dialami manusia, oleh karena itu di dalam Islam ada ibadah yang bersifat sosial seperti sedekah, zakat dan wakaf.

Wakaf adalah salah satu bentuk kegiatan ibadah yang sangat dianjurkan bagi umat Islam karna pahala wakaf akan selalu mengalir meskipun sang wakif sudah meninggal. Sebagai ibadah yang berdimensi sosial, wakaf mempunyai filosofi dan hikmah yang sangat rasional bermanfaat bagi kehidupan umat. Manfaat ini sudah terbukti dalam sejarah umat Islam sejak awal sampai kini. 
Namun meskipun umat Islam menyadari bahwa wakaf merupakan salah satu sumber ekonomi namun hingga saat ini hanya sedikit yang dimanfaatkan secara maksimal dan produktif. Padahal wakaf mempunyai cakupan pemanfaatan yang luas dan tidak sekedar untuk membangun masjid saja, padahal wakaf berpotensi sangat besar dalam mensejahterakan ummat dan mempunyai dimensi muamalah yang utama. Pada umumnya, masyarakat memahami bahwa wakaf hanya boleh digunakan untuk tujuan ibadah. Misalnya, pembangunan masjid, komplek kuburan, panti asuhan, dan pendidikan. Selain itu, pemahaman masyarakat mengenai ihwal benda wakaf juga masih sempit. Harta yang bisa diwakafkan masih dipahami sebatas benda tak bergerak, seperti tanah. Padahal wakaf juga bisa berupa benda bergerak, antara lain uang, logam mulia, surat berharga, kendaraan, hak kekayaan intelektual, dan hak sewa. Di masa pertumbuhan ekonomi yang cukup memprihatinkan ini, sesungguhnya peranan wakaf di samping instrumeninstrumen syariah lainnya, dapat dirasakan manfaatnya untuk meningkatkan taraf hidup masyarakat, khususnya di bidang ekonomi, apabila wakaf dikelola sebagaimana mestinya.

Bangsa Indonesia dapat belajar dari implementasi wakaf Al-Azhar, Kairo, Mesir. Universitas yang sudah berumur lebih dari seribu tahun ini berdiri di atas tanah wakaf. Meski Mesir silih berganti dinasti, rezim, dan generasi, harta wakaf Al-Azhar tetap terjaga. Harta wakaf Al-Azhar bukan hanya yang dipakai untuk membangun sarana pendidikan Al-Azhar, melainkan juga tersebar di seantero Mesir dalam bentuk tanah pertanian. Menurut keterangan Dr. Nur Samad Kamba, alumni Al-Azhar yang kini menjabat sebagai Sekretaris Badan Wakaf Indonesia, hampir dua pertiga tanah subur di Mesir adalah tanah wakaf milik Al-Azhar. Tanah-tanah itu dikelola dengan baik dan hasilnya dipergunakan untuk kepentingan pendidikan AlAzhar. Beasiswa Al-Azhar kepada mahasiswa asing dari berbagai penjuru dunia, termasuk Indonesia, merupakan hasil nyata dari pengelolaan wakaf produktif Al-Azhar.

Sementara itu, saat ini pengelolaan dan manajemen wakaf di Indonesia masih jauh dari kata optimal. Sebagai akibatnya cukup banyak harta wakaf terlantar dalam pengelolaannya, bahkan ada harta wakaf yang hilang. Salah satu penyebabnya adalah umat Islam pada umumnya hanya mewakafkan tanah dan bangunan sekolah, dalam hal ini wakif kurang memikirkan biaya operasional sekolah, dan nazhirnya kurang profesional. Kurang berperannya wakaf dalam memberdayakan ekonomi umat di Indonesia karena wakaf tidak dikelola secara produktif.

Kekayaan wakaf di Indonesia yang begitu banyak. Namun, secara umum pemanfaatannya masih bersifat konsumtif tradisional dan belum dikelola secara produktif, sehingga lembaga wakaf belum menyentuh dan memanfaatkannya secara optimal bagi kesejahteraan masyarakat. Sampai saat ini masih sangat sedikit wakaf yang dikelola secara produktif dalam bentuk suatu bentuk usaha yang hasilnya dapat dimanfaatkan bagi pihak-pihak yang memerlukan, termasuk fakir dan miskin. Pemanfaatan tersebut dilihat dari segi sosial, khususnya untuk kepentingan keagamaan memang efektif, tetapi 
Jurnal Ekonomi dan Perbankan Syariah

Vol. 7. No.2, Agustus 2018: 107-118, ISSN (cet): 2355-1755 | ISSN (online): 25796437

\section{9}

dampaknya kurang berpengaruh dalam kehidupan ekonomi masyarakat. Dapat dikatakan bahwa pengelolaan wakaf di Indonesia belum efektif atau tepat sasaran dalam hal menyelesaikan masalah sosial ekonomi rakyat. Untuk itu penulis perlu mengemukakan kembali konsep wakaf yang efektif dalam menyelesaikan masalah sosial ekonomi rakyat dan membangun bangsa agar lebih maju.

\section{B. LANDASAN TEORI}

Istilah wakaf berasal dari bahasa Arab, yaitu waqafa-yaqif-waqfan dan awqafa-yuqif-iqafan (as-Sarakhi, 1993/XII:27), yang secara gramatikal berarti "menahan", sedangkan menurut istilah syara "kata wakaf" berarti menahan dan memberikan manfaatnya pada jalan Allah SWT.

Dari sudut etimologi, kata (waqofa) memiliki konotasi negatif jika ditambahkan huruf hamzah diawalnya (awqofa). Ungkapan populer orangorang Arab misalnya: Sebidang tanah ditahan atau dilarang untuk dikelola oleh orang-orang miskin.

Ungkapan ini berarti tanah itu dikuasai pemerintahan sehingga orangorang tidak bisa ikut campur. Kata wakaf kemudian dipersempit dalam term fiqh, ialah menahan harta benda yang memiliki potensi manfaat tanpa merubah zat barang dengan memutus aktivitas pengolahan si pemilik (seperti menjual, memberikan dan mewariskannya) untuk kemudian disalurkan manfaatnya kepada tempat-tempat yang dibolehkan.

Para ulama fiqih mendefinisikan wakaf berbeda-beda, mazhab Syafi'iyah mendefinisikan wakaf adalah menahan harta yang dapat dimanfaatkan dengan tetap utuh bendanya untuk sesuatu yang diperbolehkan. Mazhab Malikiyah mendefinisikan wakaf memberikan manfaat selamalamanya. Mazhab Hanabilah mendefinisikan wakaf adalah menahan pokok wakaf dan menyedekahkan hasilnya (Ibn Qudamah, 1992/XIII: 184). Mazhab Hanafiyyah mendefinisikan wakaf adalah menahan harta dari kepemilikian orang lain (as-Sarakhsi, 1993/XII:27).

Pengertian wakaf tersebut menunjukan beberapa hal; pertama, wakaf dilakukan terhadap harta yang mengandung potensi manfaat dan dapat disalurkan tanpa merusak atau mengganggu eksistensi barang tersebut, semisal tanah, dan rumah. Kedua, pemilik barang tidak lagi memiliki otoritas untuk mengelola barang. Ini didasarkan bahwa pemberi wakaf (waqif) ditahan dan dilarang melakukan pengelolaan dan atau kegiatan transaksi apapun terkait barang tersebut. Berbeda halnya dengan Abu Hanifah yang berpandangan bahwa wakaf tidak memutus kepemilikan barang dari pemberi wakaf (waqif).

Wakaf mempunyai dasar hukum di dalam Al-Quran dan hadis, adapun dalil yang menjadi dasar hukum wakaf antara lain:

1. "Perbuatlah kebajikan, supaya kamu mendapat kemenangan" (QS : al-Haj : 77). 
2. “Kamu sekali-kali tidak sampai kepada kebajikan (yang sempurna) sebelum kamu menafkahkan sebagian harta yang kamu cintai. Dan apa saja yang kamu nafkahkan, maka sesungguhnya Allah mengetahui". (QS : Ali Imran : 92).

3. "Perumpamaan (nafakah yang dikeluarkan oleh) orang-orang yang menafkahkan hartanya di jalan Allah, adalah serupa dengan sebutir benih yang menumbuhkan tujuh butir, pada tiap-tiap butir menumbuhkan seratus biji. Allah melipatgandakan (ganjaran) bagi siapa saja yang Dia kehendaki. Dan Allah Maha Luas (Karunianya) Lagi Maha Mengetahui". (QS : al-Baqarah : 261).

4. "Apabila seseorang meninggal dunia maka terputus amalnya kecuali tiga hal, yaitu sedekah jariyah, ilmu yang bermanfaat, dan anak shaleh yang mendoakan orang tuanya". (HR. Muslim)(Muslim, 1986/III:1255).

5. “Umar bin Khattab pernah memperoleh tanah di Khaibar kemudian datang kepada Nabi SAW. Umar berkata:'Aku mendapatkan tanah yang sangat bagus sekali bagaimana engkau memerintahkan kepadaku?' Nabi menjawab, 'Jika kamu berkehendak tahanlah pokoknya dan sedekahkanlah hasilnya'. Umar mensedekahkan yang tidak dijual pokoknya, tidak dihibahkan, dan tidak diwariskan. Umar mensedekahkan pada orang-orang fakir, kerabat, budak, sabilillah, tamu, ibnu sabil. Boleh bagi orang yang mengurusnya mengambil sekedarnya dan memberi pada temannya tanpa menjadikan sebagai hak kepemilikan". (HR.Bukhari)(al-Bukhari, t.th/II:132)

Dalam fiqih klasik, pada umumnya wakaf harus mengandung tiga syarat:

1. Barang yang diwakafkan adalah barang tetap yang dapat diambil manfaatnya, sehingga tidak seperti mewakafkan makanan yang akan habis setelah dikonsumsi.

2. Obyek yang diberi wakaf sudah jelas, bukan yang akan ada, sehingga tidak mungkin menyerahkan harta wakaf kepada orang yang belum lahir, sudah meninggal dunia, dan masjid yang belum ada.

3. Barang yang diwakafkan bukan barang haram. Dengan demikian, tidak dibenarkan mewakafkan tempat perjudian atau tempat lokalisasi pelacuran. (Azizy, 2004:122).

Gagasan wakaf memiliki tiga potensi yang besar, yaitu: pertama, perbuatan wakaf didasarkan pada semangat kepercayaan (trust) yang sangat tinggi dari seorang wakif kepada nazhir. Kedua, aset wakaf merupakan kepemilikan Allah, dengan kata lain memiliki aspek teologis, sehingga tidak boleh dihibahkan, dijual dan dapat memberikan manfaat secara abadi. Ketiga, tujuan wakaf adalah untuk meningkatkan kesejahteraan masyarakat banyak.

Keberadaan wakaf adalah sangat dinamis dan luwes, dapat dikembangkan sesuai perkembangan zaman dengan prinsip dan tujuan Islam. Tujuan ajaran syariat Islam adalah demi tercapainya kemaslahatan manusia. 
Jurnal Ekonomi dan Perbankan Syariah

Vol. 7. No.2, Agustus 2018: 107-118, ISSN (cet): 2355-1755 | ISSN (online): 2579-

6437

\section{| 111}

Pada prinsipnya hukum Islam, berpegang pada prinsip, "jalb al-mashalih wa dar'u al-mafasid" (Menjaga kemaslahatan dan menolak kerusakan) (Abdussalam, 1985, hal.9).

Sedangkan prinsip tujuan syari'ah tidak terlepas dari tiga pokok, yaitu menjaga mashlahat dlaruriyat (kepentingan-kepentingan primer), maslahat hajiyat (kebutuhan-kebutuhan utama) dan mashlahat tahsiniyat (kepentingan peningkatan kualitas hidup). Agama Islam menjaga kemaslahatan dlaruriyat dengan memberikan kebebasan untuk melaksanakan praktik-praktik ibadah dan ketentuan hukum. (As-Syathibi, 1985, hal.4-6). Dalam hal ini, wakaf menempati urutan ketiga dari maslahat yang ditawarkan Islam, yaitu mashlahat tahsiniyat. Dengan kemaslahatan ini, wakaf berkembang sesuai dengan dinamika negara yang memiliki aset wakaf yang potensial.

\section{PEMBAHASAN}

Potensi wakaf di Indonesia dalam setahun bisa mencapai 20 T/Tahun (Mustafa Edwin Nasution- Ketua Ikatan Ahli Ekonomi Islam Indonesia). Pendayagunaan wakat merupakan potensi pendanaan yang sangat strategis dalam pemberdayaan masyarakat miskin untuk memperbaiki perekonomian mereka.

Sebagaimana kita ketahui bahwa kemiskinan masih menjadi masalah bangsa Indonesia. Statistik menunjukkan masih tingginya tingkat kemiskinan terutama penduduk pedesaan.

Tabel 1. Jumlah Penduduk Miskin, Presentase Miskin dan Garis Kemiskinan di Indonesia 2011-2017

\begin{tabular}{|c|c|c|c|c|c|c|c|c|}
\hline \multirow{2}{*}{ Tahun } & \multicolumn{3}{|c|}{$\begin{array}{c}\text { Jumlah Penduduk } \\
\text { Miskin }\end{array}$} & \multicolumn{3}{c|}{$\begin{array}{c}\text { Persentase Penduduk } \\
\text { Miskin }\end{array}$} & \multicolumn{2}{c|}{$\begin{array}{c}\text { Garis Kemiskinan } \\
\text { (Juta/Kapita/Bulan) }\end{array}$} \\
\cline { 2 - 10 } & Kota & Desa & $\begin{array}{c}\text { Kota+ } \\
\text { Desa }\end{array}$ & Kota & Desa & $\begin{array}{c}\text { Kota+ } \\
\text { Desa }\end{array}$ & Kota & Desa \\
\hline Mar-11 & 11,05 & 18,97 & 30,02 & 9,23 & 15,72 & 12,49 & 253016 & 213395 \\
\hline Sep-11 & 10,95 & 18,94 & 29,89 & 9,09 & 15,59 & 12,36 & 263594 & 223181 \\
\hline Mar-12 & 10,65 & 18,49 & 29,13 & 8,78 & 15,12 & 11,96 & 267408 & 229226 \\
\hline Sep-12 & 10,51 & 18,09 & 28,59 & 8,60 & 14,70 & 11,66 & 277382 & 240441 \\
\hline Mar-13 & 10,33 & 17,74 & 28,07 & 8,39 & 14,32 & 11,37 & 289042 & 253273 \\
\hline Sep-13 & 10,63 & 17,92 & 28,55 & 8,52 & 14,42 & 11,47 & 308826 & 275779 \\
\hline Mar-14 & 10,51 & 17,77 & 28,28 & 8,34 & 14,17 & 11,25 & 318514 & 286097 \\
\hline Sep-14 & 10,36 & 17,37 & 27,73 & 8,16 & 13,76 & 10,96 & 326853 & 296681 \\
\hline
\end{tabular}




\begin{tabular}{|c|c|c|c|c|c|c|c|c|} 
Mar-15 & 10,65 & 17,94 & 28,59 & 8,29 & 14,21 & 11,22 & 342541 & 317881 \\
\hline Sep-15 & 10,62 & 17,89 & 28,51 & 8,22 & 14,09 & 11,13 & 356378 & 333034 \\
\hline Mar-16 & 10,34 & 17,67 & 28,01 & 7,79 & 14,11 & 10,86 & 364527 & 343647 \\
\hline Sep-16 & 10,49 & 17,28 & 27,76 & 7,73 & 13,96 & 10,7 & 372114 & 350420 \\
\hline Mar-17 & 10,67 & 17,1 & 27,77 & 7,72 & 13,93 & 10,64 & 385621 & 361496 \\
\hline Sep-17 & 10,27 & 16,31 & 26,58 & 7,26 & 13,47 & 10,12 & 400995 & 370910 \\
\hline
\end{tabular}

Sumber: Badan Pusat Statistik (BPS)

Menurut BPS, jumlah penduduk miskin-penduduk dengan pengeluaran per kapita per bulan di bawah garis kemiskinan-pada Maret 2016 di Indonesia mencapai 28,01 juta jiwa atau sebesar 10,86 persen dari total jumlah penduduk Indonesia. Walaupun dari sisi jumlah kemiskinan di pedesaan menurun, namun secara persentase penduduk miskin meningkat. Pada bulan Maret 2015 persentase penduduk miskin pedesaan sebesar 14,21 persen, lalu turun padaSeptember 2015 menjadi 14,09 persen kemudian naik 0,02 persen di bulan Maret 2016 menjadi 14,11 persen. Bila mengacu data Nilai Tukar Petani (NTP) yang terus menurun dari 102,55 pada Januari 2016 menjadi 101,47 pada Juni 2016 maka wajar jika persentase kemiskinan di perdesaan meningkat, karena usaha pertanian menurun(Badan Pusat Statistik (BPS), 2017:112).

Di masa pertumbuhan ekonomi yang cukup memprihatinkan ini, sesungguhnya peranan wakaf di samping instrumen-instrumen syariah lainnya, diharapkan dapat dirasakan manfaatnya untuk meningkatkan taraf hidup masyarakat, khususnya di bidang ekonomi, apabila wakaf dikelola sebagaimana mestinya.

Dalam sejarah Islam, praktik wakaf telah memberi dampak sosial ekonomi kepada masyarakat. Misalnya, di Turki wakaf uang pernah berkembang dengan pesat, di Mesir wakaf dalam bentuk saham telah dilakukan, serta di Jerussalem banyak wakaf dalam bentuk dapur umum yang memberi makanan kepada fakir miskin. Dua contoh terakhir ini tidak pernah dipraktikkan di Indonesia. Hal ini bukan karena perbedaan sumber hukum, melainkan perbedaan interpretasi dan kebutuhan masyarakat. Begitu juga praktik wakaf di Indonesia mengalami transformasi sesuai dengan perkembangan masyarakat. Dari abad ke-18 sampai awal abad ke-20, di Indonesia tidak ada inovasi wakaf tetapi yang dominan dalam bentuk tanah, kuburan, sawah, kebun, bangunan sekolah, dan pesantren. Hal itu dapat dilihat dari grafik penggunaan tanah wakaf di Indonesia berikut ini: 
Jurnal Ekonomi dan Perbankan Syariah

Vol. 7. No.2, Agustus 2018: 107-118, ISSN (cet): 2355-1755 | ISSN (online): 25796437

\section{| 113}

Gambar 1. Penggunaan Tanah Wakaf Indonesia

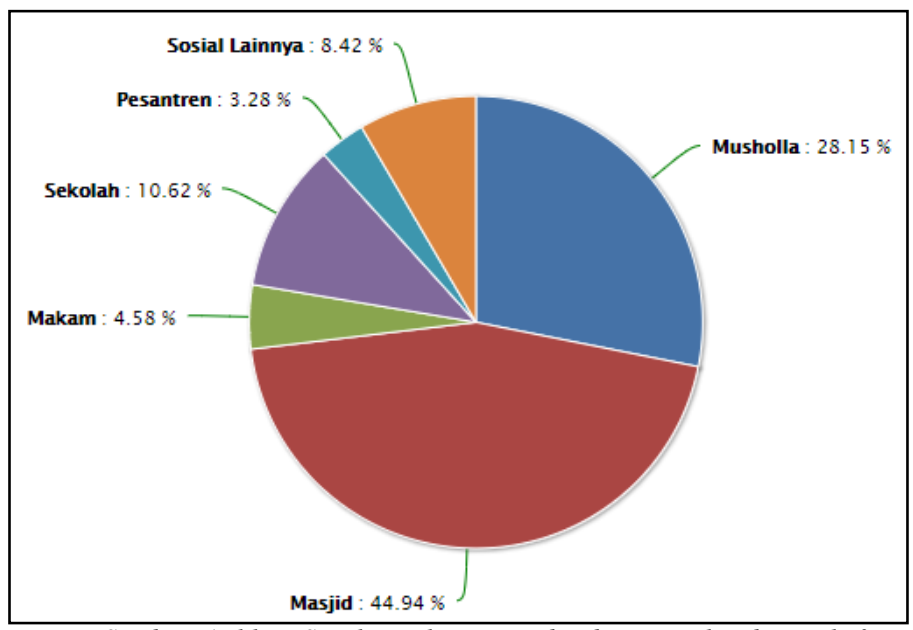

Sumber: Aplikasi Siwak Direktorat Pemberdayaan Zakat dan Wakaf

Indonesia saatnya belajar dari Negara Bangladesh, tempat kelahiran instrumen eksperimental melalui Social Investment Bank Limited (SIBL) yang menggalang dana dari orang-orang kaya untuk dikelola dan disalurkan kepada rakyat dalam bidang pendidikan, kesehatan, kesejahteraan sosial melalui mekanisme produk funding baru berupa Sertifikat Wakaf Tunai (Cash Waqf Certificate) yang akan dimiliki oleh pemberi dana tersebut. Dalam instrumen keuangan baru ini Sertifikat Wakaf Tunai merupakan alternatif pembiayaan yang bersifat sosial dan bisnis serta partisipasi aktif dari seluruh warga negara yang kaya untuk berbagi kebahagiaan dengan saudaranya dalam menikmati pendidikan, kesehatan dan kesejahteraan yang baik.

Dalam hal pendidikan, pemanfaatan wakaf tunai dapat dilakukan dengan mendirikan madrasah, pesantren, perpustakaan, maupun universitas lembaga-lembaga Islam terkemuka seperti Al-Azhar University Kairo, Universitas Zaituniyyah di Tunis, dan ribuan Madaris Imam Lisesi di Turki mampu bertahan berabad-abad lamanya dan memberikan beasiswa kepada jutaan mahasiswa selama lebih 1000 tahun dari seluruh penjuru dunia. Universitas-universitas tersebut bukanlah lembaga pendidikan yang sepenuhnya berorientasi profit.

Mereka adalah lembaga pendidikan yang lebih bercorak sosial. Apakah mungkin pendanaannya hanya mengandalkan sedekah dan infak masyarakat setempat, sementara mereka harus membiayai operasionalnya sendiri, membangun sarana belajar-mengajar tambahan, dan memberikan beasiswa kepada jutaan mahasiswa yang mana Indonesia termasuk paling banyak menikmati fasilitas ini. Salah satu jawabannya adalah mereka telah berhasil mengembangkan cash waqf (wakaf tunai) sebagai sumber dana untuk pengembangan dan operasional pendidikan. 
Di Spanyol, fasilitas rumah sakit yang melayani baik Muslim maupun non Muslim, juga berasal hasil pengelolaan asset wakaf. Dana hasil pengelolaan asset wakaf juga digunakan untuk membantu pembangunan Pusat Seni dan telah sangat berperan bagi perkembangan arsitektur Islam terutama arsitektur dalam pembangunan masjid, sekolah, dan rumah sakit.Salah satu permasalahan bagi UKM di Indonesia adalah masalah permodalan.

Selain itu, wakaf harusnya juga bermanfaat untuk UKM yang ada di Indonesia. Modal yang kurang seakan menjadikan UKM di Indonesia kurang berkembang saat ini. Dengan adanya Badan wakaf Indonesia, dimana di dalamnya terdapat pengelolaan wakaf tunai maka dapat dijadikan solusi bagi para pedagang UKM untuk mendapatkan modal dan digunakan dalam rangka mengembangkan UKM masyarakat.

Maka dari itu, wakaf sebagai salah satu jenis filantropi dalam ekonomi Islam yang memiliki ciri keabadian perlu dikelola secara optimal untuk dikembangkan agar dapat menghasilkan dan berguna untuk pengembangan aktivitas perekonomian umat. Sudah saatnya akaf terarah kepada kegiatan yang produktif. Supaya pada nantinya wakaf dapat berkembang dan berfungsi untuk membangun bangsa.

Dari penjelasan di atas dapat disimpulkan bahwa wakaf di Indonesia cukup banyak tetapi belum dapat mewujudkan kesejahteraan sosial, faktor penyebabnya yaitu:

1. Pemahaman wakaf yang masih kurang.

2. Pengelolaan wakaf yang belum optimal.

3. Terbatasnya benda yang diwakafkan dan nazhir wakaf.

Untuk itu perlu dirumuskan kembali bagaimana konsep wakaf yang efektif atau tepat sasaran sesuai fungsinya mewujudkan kesejahteraan sosial dalam membangun bangsa.

1. Memperbaiki pemahaman umat tentang wakaf

Harta benda wakaf menurut UU. no. 41 tahun 2004 tentang wakaf yaitu:

a) Harta wakaf tidak bergerak

i. Hak atas tanah sesuai dengan ketentuan peraturan perundangundangan yang berlaku baik yang sudah maupun yang belum terdaftar.

ii. Bangunan atau bagian bangunan yang berdiri di atas tanah.

iii. Tanaman dan benda lain berkaitan dengan tanah

iv. Hak milik atas satuan rumah susun

v. Benda tidak bergerak lain sesuai dengan ketentuan syariah dan peraturan perundangan-undangan yang berlaku.

b) Harta wakaf bergerak

i. Uang. Wakaf tunai inilah sedang digalakkan menjadi wakafwakaf produktif.

ii. Logam mulia.

iii. Surat berharga

iv. Kendaraan

v. Hak atas kekayaan intelektual (HAKI)

vi. Hak sewa 
vii. Benda bergerak lain sesuai dengan ketentuan syariah dan peraturan perundangan-undangan yang berlaku.

2. Pemberdayaan wakaf

Wakaf yang diberdayakan sehingga menghasilkan sesuatu yang bermanfaat lebih dikenal sekarang dengan istilah wakaf produktif. Wakaf produktif juga dapat diartikan sebagai proses pengelolaan benda wakaf untuk menghasilkan barang atau jasa yang maksimum dengan modal yang minimum (Jaih Mubarok, 2008:1516). Sedangkan menurut Munzir Qahaf, wakaf produktif adalah memindahkan harta dari upaya konsumtif menuju produktif dan investasi dalam bentuk modal produksi yang dapat memproduksi dan menghasilkan sesuatu yang dapat dimanfaatkan pada masa-masa mendatang, baik oleh pribadi, kelompok maupun oleh umum. Dengan demikian, wakaf produktif merupakan kegiatan menabung dan berinvestasi secara bersamaan (Qahaf, 2006: 58).

Said dan Lim melakukan penelitian tentang bagaimana strategi untuk memberdayakan aset wakaf menjadi produktif, menurutnya ada 5 (lima) langkah strategi untuk memberdayakan wakaf agar menjadi wakaf produktif (Said and Lim, 2005: 6-7) yaitu:

1. Mengenali potensi perputaran harta wakaf dengan melihat sejarah atau model wakaf yang sudah berjalan dan melakukan pembaruan pada sistem wakaf.

2. Memfasilitasi pengembangan model wakaf modern dengan menerapkan teknik manajemen modern pada wakaf, sepanjang tujuannya tidak bertentangan dengan prinsip-prinsip syari'ah.

3. Mempromosikan filantropi Islam melalui wakaf, sehingga wakaf dapat menjadi tulang punggung bagi masyarakat dan berpotensi memainkan peran penting dalam pelayanan masyarakat. Disamping itu, wakaf produktif dapat menjadi alternatif pada masa krisis ketika pemerintah sudah tidak sanggup lagi memenuhi kebutuhan masyarakat.

4. Memodernisasi administrasi wakaf, sehingga struktur manajemen wakaf dapat menjadi lebih efisien, transparan dan responsif serta menjalin kerjasama teknis dan bertukar pengalaman dengan lembaga pendidikan, organisasi internasional dan negara lain untuk mengembangkan isvestasi wakaf.

5. Memproduktifkan wakaf yang sebelumnya tidak produktif dengan membangkitkan komitmen dari wakif, nazir, investor dan masyarakat sekitarnya yang mengetahui benefit dari wakaf tersebut. 
Ada tiga hal mendasar dalam implementasi pengembangan wakaf produktif: pertama, pemenuhan kebutuhan-kebutuhan dasar (basic needs) masyarakat seperti makan, tempat tinggal, pendidikan, kesehatan dan sebagainya. Kedua, mengupayakan peningkatan kesempatan yang setara bagi semua orang, terutama mereka yang paling tidak beruntung dalam masyarakat. Ketiga, melakukan perubahan struktural mencakup perubahan sistem dan pranata sosial yang menjamin kesejahteraan umat (Najib\&al-Makassary (ed.), 2006 :22).

Di seluruh dunia, wakaf produktif sudah menjadi paradigma utama dalam mengelola aset. Beberapa implementasi yang dapat diterapkan di Indonesia yaitu:

a. Mendirikan Bank wakaf.

b. Mendirikan perusahaan bisnis dan industri.

c. Membuat real estate berbasis wakaf, penghasilannya menjadi milik lembaga pengelola wakaf yang nantinya dana ini dialokasikan untuk kesejahteraan umat.

d. Memberdayakan wakaf tanah pertanian dan peternakan.

e. Kerjasama dengan investor untuk membangun gedung pertokoan, rumah sakit, supermarket, hotel dan lainnya di atas tanah wakaf. Kerjasama ini tidak bernilai materi secara langsung, melainkan kerjasama yang saling menguntungkan, di mana nazir diberi hak untuk mengelola gedung yang dibangun di atas tanah wakaf dan hasilnya digunakan untuk kepentingan umat.

f. Mendirikan perusahaan milik gabungan (syirkah milk).

g. Investasi kepada UMKM umat.

h. Wakaf untuk pendidikan. Negara-negara Islam telah banyak sukses dalam wakaf pendidikan ini, contohnya di Mesir. Tidak hanya berwakaf dengan gedung dan peralatan sekolah. Tetapi memanfaatkan wakaf produktif yang labanya dipakai untuk pengembangan pendidikan, seperti pemberian beasiswa bagi pelajar muslim, proyek penerjemahan al-Qur'an ke dalam berbagai bahasa, dan penerbitan buku-buku Islam.

i. Wakaf untuk sarana dan prasarana kesehatan.

j. Wakaf sumur untuk kebutuhan air bersih, irigasi, wudhu, MCK, dll.

k. Wakaf untuk infrastruktur desa.

3. Pengelolaan wakaf berbasis organisasi dan badan hukum

Kebanyakan kendala pengelolaan wakaf adalah nazhir perseorangan yang bekerja paruh waktu dan tidak mendapat imbalan. Dan persebaran wakaf juga masih rendah, jika tidak dikelola berbasis organisasi. Sejumlah $62.23 \%$ dari seluruh penduduk miskin di Indonesia tinggal di daerah pedesaan. Oleh sebab itu diperlukan pengelolaan wakaf berbasis organisasi dan badan hukum, sehingga 
nazhir dapat bekerja secara profesional, terlatih dengan ilmu-ilmu yang dibutuhkan dan mendapat imbalan yang memadai, selanjutnya penyebaran dana wakaf akan bisa didistribusikan secara merata oleh organisasi tsb. Sebagai contoh implementasi pengelolaan yang baik jika nazhir profesional dan handal yaitu masjid bisa diproduktifkan dan menghasilkan ekonomi dengan mendirikan lembaga-lembaga perekonomian Islam di dalamnya, seperti BMT, lembaga zakat, wakaf, mini market, dan sebagainya. Dengan pengelolaan wakaf berbasis organisasi juga dapat diupayakan peningkatan terobosan inovasi dan kreatifitas dalam membuat program-program, penggalangan dana lebih agresif dalam kegiatan promosi yang memanfaatkan teknologi informasi, serta penerbitan sertifikat wakaf dalam beberapa pilihan nominal yang dapat meningkatkan antusiasme umat untuk berwakaf.

Organisasi pengelola wakaf ini dapat berupa organisasi dari kementrian agama, organisasi sosial independen, dan lain-lain. Sebagai contoh di Indonesia sudah ada Badan Wakaf Indonesia (BWI) sebagai pembina utama semua nazhir di Indonesia, Rumah wakaf, ACT, PKPU, Tabung Wakaf Indonesia, Yayasan Griya Yatim dan Du'afa, dll. Saat ini, nazhir wakaf uang yang terdaftar di BWI menjadi 56 lembaga.

Pemberdayaan wakaf produktif berbasis organisasi ditandai dengan tiga ciri utama: pertama, pola manajemen wakaf harus terintegrasi dan dana wakaf dapat dialokasikan untuk programprogram pemberdayaan dengan segala macam biaya yang tercakup di dalamnya. Kedua, asas kesejahteraan nazir. Pekerjaan sebagai nazir tidak lagi diposisikan sebagai pekerja sosial, melainkan sebagai profesional yang bisa hidup layak dari profesi tersebut. Ketiga, asas transparansi dan tanggung jawab (accountability). Badan wakaf dan lembaga yang dibantunya harus melaporkan proses pengelolaan dana setiap tahunnya kepada umat (Antonio, 2007: viii).

\section{PENUTUP}

Wakaf di Indonesia cukup banyak tetapi belum dapat mewujudkan kesejahteraan sosial, faktor penyebabnya yaitu: 1) Pemahaman wakaf yang masih kurang, 2) Pengelolaan wakaf yang belum optimal, 3) Terbatasnya benda yang diwakafkan dan nazhir wakaf.

Untuk itu perlu dirumuskan kembali bagaimana konsep wakaf yang efektif atau tepat sasaran sesuai fungsinya mewujudkan kesejahteraan sosial dalam membangun bangsa. Konsep tersebut yakni 1) Memperbaiki pemahaman umat tentang wakaf. Harta benda wakaf menurut UU. no. 41 tahun 
2004 tentang wakaf yaitu: Harta tidak bergerak (tanah, bangunan/bagian, tanaman dan benda lain berkaitan dengan tanah, hak milik atas satuan rumah susun, sumur, benda tidak bergerak lain.) dan Harta bergerak (Uang, Logam mulia,Surat berharga, kendaraan, Hak atas kekayaan intelektual (HAKI), Hak sewa dan benda bergerak lain). 2) Pemberdayaan wakaf, harta benda wakaf yang telah disebutkan di atas dapat diberdayakan agar menjadi harta benda yang produktif, laba dari wakaf produktif tersebut dapat dimanfaatkan untuk kepentingan umat terutama di bidang pendidikan, kesehatan, pemenuhan kebutuhan penduduk miskin. 3) Pengelolaan wakaf berbasis organisasi dan badan hukum, hal ini dapat menghasilkan nazhir yang profesional, pendistribusian yang merata dan tepat sasaran, penggalanan dana yang inovatif dan aktual. Dari perumusan konsep di atas jika diterapkan dengan sebaikbaiknya, maka kebutuhan-kebutuhan primer masyarakat akan terpenuhi, bahkan dana-dana sosial juga akan tersedia dari hasil pengelolaan wakaf produktif.

\section{E. DAFTAR PUSTAKA}

Abdussalam, Izz ad-Din ibn, 1985, Qawaid al-Ahkam, Beirut: Dar al-Fikr.

Abu Zahrah, Muhammad, 2005, Muhadarat fi al-Waqf, Cairo: Dar al-Fikr al'Arabi.

Antonio, Muhammad Syafi'i, 2007, "Pengelolaan Wakaf Secara Produktif," dalam Achmad Djunaidi dan Tabieb al-Asyhar, Menuju Era Wakaf Produktif, Jakarta: Mumtaz Publising.

A. Karim, Adiwarman, Wakaf Tunai untuk Investasi, dalam Makalah Seminar Wakaf Tunai untuk Investasi Bisnis Bank Nasional Indonesia-Dompet Dhuafa', Republika, Jakarta, 8 Mei 2003.

Azizy, A. Qadri, 2004, Membangun Fondasi Ekonomi Umat, Yogyakarta: Pustaka Pelajar.

Bukhari, al-, 1987, Jami' Sahih al-Mukhtasar, Beirut: Dar Ibn Katsir.

Departemen Agama, Fiqih Wakaf, Jakarta: Direktorat Wakaf, 2007

Direktorat Pemberdayaan Wakaf Depag RI, data direlease pada tahun 2009.

Ibn Qudamah, t.th, al-Mughni, Riyad: Maktabah ar-Riyad al-Hadisah.

Mubarok, Jaih, 2008, Wakaf Produktif, Bandung: Simbiosa Rekatama Media.

Muslim, 1986, Shahih Muslim, Beirut: Dar al-Fikr.

Najib, Tuti A., Ridwan al-Makassary (ed.), 2006, Wakaf, Tuhan, dan Agenda Kemanusiaan: Studi tentang Wakaf dalam Perspektif Keadilan Sosial di Indonesia, Jakarta: kerjasama The Ford Foundation dan CSRC.

Said, M. Siraj and Lim, Hilary, 2005, Waqf (Endowment) and Islamic Philantrophy, United Kingdom: University of East London 